\title{
COMT and GAD1 gene polymorphisms are associated with impaired antisaccade task performance in schizophrenic patients
}

\author{
Anna V. Kirenskaya ${ }^{1}$ (D) Zinaida I. Storozheva $^{1} \cdot$ Marina A. Gruden $^{2} \cdot$ Robert D. E. Sewell $^{3}$
}

Received: 23 July 2017 / Accepted: 4 February 2018 / Published online: 10 February 2018

(c) The Author(s) 2018. This article is an open access publication

\begin{abstract}
Genetic influences modulating executive functions engaging prefrontal cortical brain systems were investigated in 141 male subjects. The effects of variations in two genes implicated in dopamine and GABA activities in the prefrontal cortex: rs4680 (Val158/Met polymorphism of the catechol-o-methyltransferase gene-COMT) and $r s 3749034$ (C/T) substitution in the promoter region of the glutamic acid decarboxylase gene $(G A D l)$ were studied on antisaccade (AS) performance in healthy subjects and schizophrenic patients. Genotyping revealed a trend towards a reduced proportion of COMT Val/Met heterozygotes and a significantly increased frequency of the GAD1 rs $3749034 \mathrm{C}$ allele in schizophrenic patients relative to controls. Patients had elevated error rates, increased AS latencies and increased latency variability (coefficient of variation) compared to controls. The influence of polymorphisms was observed only in patients but not in controls. A substantial effect of the COMT genotype was noted on the coefficient of variation in latency, and this measure was higher in Val homozygotes compared to Met allele carriers $(p<0.05)$ in the patient group. The outcome from $r s 3749034$ was also disclosed on the error rate (higher in $\mathrm{T}$ carriers relative to $\mathrm{C}$ homozygotes, $p<0.01$ ) and latency (increased in $\mathrm{C}$ homozygotes relative to $\mathrm{T}$ carriers, $p<0.01$ ). Binary logistic regression showed that inclusion of the genotype factor (i.e., selective estimation of antisaccade measures in CC carriers) considerably increased the validity of the diagnostic model based on the AS measures. These findings may well be derived from specific genetic associations with prefrontal cortex functioning in schizophrenia.
\end{abstract}

Keywords COMT rs 4680 polymorphism · GAD1 rs3749034 polymorphism · Antisaccade task · Schizophrenia

\section{Introduction}

There are numerous reports from structural and neuroimaging studies of disturbed prefrontal cortical (PFC) function in schizophrenia [1-3]. Impaired performance in complex tasks critically engaging prefrontal cortical systems requiring advanced cognitive processes are collectively known as executive functions and they are an important component

Robert D. E. Sewell

sewell@cardiff.ac.uk

1 Federal Medical Research Centre of Psychiatry and Narcology, Kropotkinsky Lane. 23, 119034 Moscow, Russian Federation

2 Federal State Budgetary Scientific Institution "P. K. Anokhin Research Institute of Normal Physiology”, Baltiskaya St., 8, 125315 Moscow, Russian Federation

3 Cardiff School of Pharmacy and Pharmaceutical Sciences, Redwood Building, Cardiff University, Cardiff CF10 3NB, UK underlying many of the cognitive deficits observed in schizophrenia $[1,4,5]$. In the context of this, it has been suggested that cognitive deficits related to executive functions are particularly heritable $[6,7]$.

The genetic contribution to the etiology of schizophrenia is considerable, and recent molecular genetic studies indicate that several genes may be associated with the disorder. In an endeavor to expose susceptibility genes, schizophrenia research has focused on an endophenotypic approach. Endophenotypes are relatively simple, distinct and measurable biobehavioral characteristics. Individually, they are intermediary between the cellular effects of susceptibility genes manifesting psychopathology and they are undoubtedly determined by fewer genes than the more complex phenotype of schizophrenia [1, 8-11]. The antisaccade (AS) task has been employed as an endophenotype, and performance impairment in this task is considered an indicator of genetic propensity towards fronto-striatal pathologies such as schizophrenia [12]. 
AS performance involves a range of executive processes that rely heavily on frontal lobe structures including directed attention and inhibition, task management, planning, monitoring, and coding of representations in working memory $[13,14]$. The importance of frontal cortical regions in AS performance has been established using functional brain imaging [15-19], and examination of event-related cortical potentials [20-22]. Increased neural firing in the prefrontal cortex before antisaccades has also been demonstrated in several studies in non-human primates [23-25].

The performance deficit exhibited by schizophrenic patients in the AS task has been interpreted as support for prefrontal cortical dysfunction and abnormalities in several related prefronto-centric circuits. It is notable that antisaccade deficits occur in unaffected family members of schizophrenic patients, and the large difference in effect size between schizophrenia probands, relatives and normal healthy controls renders the antisaccade task highly appropriate for endophenotype genetic studies [12, 26]. However, only a limited number of investigations have been carried out in this regard [27-30].

Numerous evidence-based treatments for psychosis point to the dopaminergic and other neurotransmitter systems, upon which much supportive scientific data has accumulated. In relation to this, an association between genes linked to dopamine function and schizophrenia has been widely established in candidate-gene studies [1, 9-11, 31]. However, genome-wide association studies (GWAS) have confirmed relatively few of these associations though a postGWAS has identified not only COMT but also GADI among a selection of schizophrenia risk genes [32]. There can be discrepancy between the results of pre-GWAS (candidategene) and GWAS studies with respect to disease. Consequently, an omnigenic model has been proposed in which assorted genes expressed in disease-relevant cells may perturb the functions of core disease-related genes [33] and this concept is likely to be the focus of future debate. In the case of schizophrenia, the dopaminergic pathways are one of the main targets of treatment, and genes participating in the regulation of dopaminergic neurotransmission are among the most relevant hypothesis-driven candidates. Since hypofrontality greatly contributes to cognitive deficit in schizophrenia, the study of genes linked to prefrontal dopamine activity contributes towards the understanding of the neurophysiologic and genetic mechanisms of the disease.

The catechol- $O$-methyltransferase gene (COMT) produces an enzyme that degrades catecholamines and is known to be one of the key factors in the regulation of dopamine level in the prefrontal cortex (PFC) [34]. COMT is among the so-called "hypothesis-driven" candidate genes for the risk of schizophrenia [32]. A Val158Met single nucleotide polymorphism of the COMT gene ( $r$ 4680) influences its enzyme activity. Thus, the Met/Met variant displays $40 \%$ less enzymatic activity than the Val/Val variant [35], and is consequently associated with higher dopamine levels in the prefrontal and anterior cingulate cortex [36]. The COMT Val158Met polymorphism correspondingly affects several cognitive functions including attention and executive control [37]. It has also been found that the Val/Val genotype is associated with smaller grey matter density in the anterior cingulate cortex [38] hippocampus, amygdala-uncus and middle temporal gyrus [39].

A dopamine-GABA interplay in the prefrontal cortex sustains working memory and attention [40]. Moreover, schizophrenia is associated with alterations in several markers of GABA neurotransmission in multiple cortical regions, including the prefrontal, primary motor, primary visual, and anterior cingulate cortices [41, 42-45]. GABAergic activity strongly depends on glutamic acid decarboxylase (GAD67), the enzyme that metabolizes glutamate to GABA and is responsible for the production of the majority of GABA in the brain [45]. Like COMT, the GADlgene that encodes GAD67 is a hypothesis-driven gene-candidate for the risk of schizophrenia [32]. Downregulation of GAD67 in the fastspiking parvalbumin-positive interneurons of the dorsolateral prefrontal cortex (DLFPC) is an authenticated result in postmortem schizophrenics [46, 47], though this finding has not yet been followed up in genetic studies. The polymorphism rs 3749034 (C/T substitution in the 5'-untranslated region in intron 1) is one of the few polymorphisms of GADI with identified functional consequence. The $\mathrm{C}$-allele of the polymorphism $r s 3749034$ is associated with a decreased level of transcription of the enzyme, a genetic risk for childhood onset of schizophrenia and decreased cortical thickness [48-50]. More recently, a T-allele association with lower white matter fractional anisotropy (FA) has been demonstrated, as well as the effects of lower white matter FA on poor working memory performance and frontal executive functioning that are independent of diagnosis [51].

Despite the fact that a number of investigations concerning associations between COMT and GADI genes with schizophrenia have been performed, the conclusions from these reports are somewhat open to debate. The majority of studies using intermediate phenotypes have examined the influence of a single genetic variant on brain activity and behavior. More recent work suggests that considering the effects of a gene in the context of additional and interacting factors may further elucidate gene-brain-behavior relationships.

The approach that may provide a more comprehensive understanding of the phenotypic effects of genetic variations is the study of gene-trait $(\mathrm{G} \mathrm{x} \mathrm{T})$ interaction [52]. A trait may indicate a psychological characteristic or the presence or absence of a diagnosis in research on psychopathology. It may also describe a variation in the general organismic context in which any single gene operates. Emerging from 
this, it is important that studies directly comparing genetic influences on neurophysiological phenotypes are performed in both healthy persons and schizophrenic patients. This approach may also be fruitful for developing diagnostic models that include genetic and neurophysiological data, although such studies are scarce.

To study the role of genetic influences in modulating behavior during cognitive control related to PFC networks, we investigated the effects of polymorphisms of COMT and $G A D 1$ genes on antisaccade performance in healthy controls versus schizophrenic patients. Bearing in mind that sexual dimorphism is a phenotypic consequence of genes [53], only male subjects were recruited to the study. Dominant handedness is also an important human characteristic tendency and relationships between handedness and personality traits, cognitive styles, as well as psychopathology have been established. There is also evidence of lateralized activity in DA neurotransmitter pathways in the human brain [54]. Thus, an interaction between handedness and genetic variants can be assumed, therefore only right-handed subjects were selected for the study.

Additionally, taking into account the genotypes studied, we assessed the possibility of using AS data as a predictor in a diagnostic model for schizophrenia.

\section{Experimental procedures}

\section{Participants}

A total of 141 male subjects (aged 19-54 years) participated in the study. Both schizophrenia patients (SCH group, $n=78$ ) and healthy volunteer controls (CON group, $n=63$ ) were recruited and all participants were right-handed males.

The patients (mean age $31.8 \pm 1.2$ years) were admitted to the Serbsky National Centre for Social and Forensic Psychiatry to undergo examination: 75 patients were criminal offenders, and 3 individuals were examined within the framework of civil litigation. Most of the patients (63 subjects) were classified as paranoid (F20.06), 7 patients had undifferentiated schizophrenia (F20.3), 3 patients had residual schizophrenia (F20.5) and 4 patients had simple schizophrenia (F20.6) according to ICD-10. Current patient symptomatology was assessed using the Positive and Negative Symptom Scale (PANSS). The mean sum of PANSS scores was $85.36 \pm 1.50$.

None of the patients displayed acute symptoms and they were free from medication for a period of approximately one month before investigation and prior to initiation of drug treatment. Healthy participants (63 subjects, mean age $25.8 \pm 0.55$ years) were evaluated by a psychiatrist to exclude any psychiatric diagnosis. Individuals with a history of neurological disorder, head trauma with loss of consciousness, substance abuse, or other medical conditions that might conceivably affect brain functioning were excluded from participation in the study. After a detailed description of the study, written informed consent for the investigation was obtained from all subjects in accordance with the local ethics committee of the Federal Medical Research Centre of Psychiatry and Narcology, Moscow, Russian Federation and the study was performed in accordance with the ethical standards laid down in the 1964 Declaration of Helsinki.

\section{Genotyping}

Extraction of DNA from saliva samples was done with MagMAX $^{\mathrm{TM}}$ DNA Multi-Sample Ultra Kits (Applied Biosystems Cat No A25597). Determination of both COMT Val158Met and GAD1 rs 3749034 polymorphisms was performed using real-time polymerase chain reaction using TaqMan ${ }^{\circledR}$ SNP Genotyping Assays C__25746809_50 for rs4680 and C__2177452_1 for rs3749034 (Applied Biosystems, USA) with LightCycler ${ }^{\circledR}$ Nano Instrument, Roche Molecular Systems Inc, USA.

\section{Antisaccade study procedure}

Experiments were carried out in a darkened room. The subjects were seated $100 \mathrm{~cm}$ in front of a board with 3 red light-emitting diodes $5 \times 5 \mathrm{~mm}$ (LEDs) (one central and two peripheral LEDs located $10^{\circ}$ to the left and right of one positioned centrally). The central LED was used as the fixation point (FP) and the two other LEDs were used as peripheral targets (PT) (Fig. 1, panel 1 and 2). Participants performed antisaccades and were instructed to look as quickly as possible at the horizontal mirror position of the PT (Fig. 1, panel 3). During the experiment, the FP was extinguished simultaneously with PT onset. The duration of the interval between the FP and PT onset varied between 1200 and $1400 \mathrm{~ms}$ and the PT duration was set at $100 \mathrm{~ms}$. Left or right target locations were randomly chosen for each trial. A correction visual stimulus at the mirror position was presented 1.5-2.0 s after the PT onset (Fig. 1, panel 4). To initiate each trial, the subject pressed and held down a mouse button with the right index finger, and FP was switched on 100-1500 ms after the press. The mouse was located on an elbow-rest for convenience. The button press was introduced in the experimental paradigm to increase attention level and behavioral engagement in the task, because these factors are generally reduced in schizophrenic patients. The LEDs were controlled by a custom-designed computer program and all intervals were varied randomly. During every experiment, 3-4 blocks each consisting of 45 trials was presented. Most frequently, 3 blocks (135 trials in total) were presented; 4 blocks were presented in the cases of patients displaying 


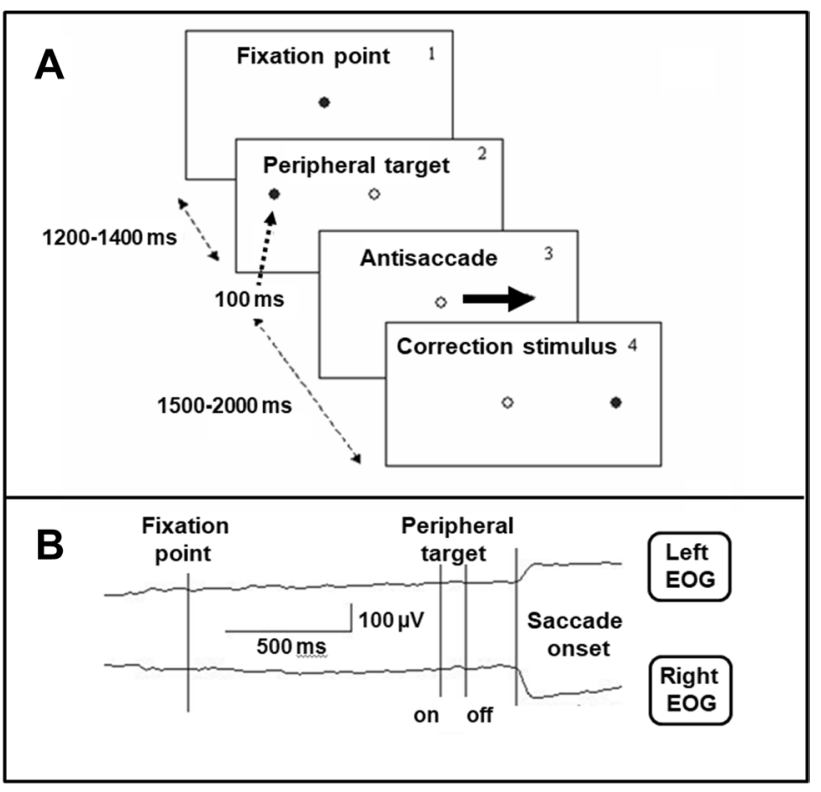

Fig. 1 Antisaccade experimental paradigm and examples of Electrooculogram (EOG) recording. a Experimental design of the visual stimuli presentation (dark circle—stimulus switched "on"; light circle—stimulus switched "off"). b Example of EOG recording

poor task performance. The rest interval imposed between the blocks lasted 3 min and a short pre-training session was introduced before the main experiment.

\section{Recording and data analysis}

A horizontal electrooculogram (EOG) was recorded via skin electrodes placed at the outer canthi of both eyes with the left earlobe as recording reference using an EEG-24 AC amplifier (MBN, Russia). The EOG channel was used for automatic saccade onset detection and for measuring both saccade latency and direction. Saccade onset was defined as a starting point of EOG deflection exceeding a predetermined threshold by slope, and where the amplitude exceeded an EOG standard variation value. The sign of deflection determined the saccade direction and each individual trial was classified by means of latency and direction as being correct or incorrect. Regular saccades only (with latency $>120 \mathrm{~ms}$ ) [13] were included in the analysis. The following performance indices were obtained:

(1) antisaccade reflexive error rate which reflected the percentage of error trials over the total number of valid trials, (2) latency of correct antisaccades which was defined as the time (ms) from target to saccade onset, (3) coefficient of variation of the latency $(\mathrm{CV}, \%)$ for correct saccades as a measure of intra-individual latency variability.

\section{Adjustment of groups for age}

Age was differentially distributed across groups. Accordingly, the mean age of the schizophrenic patients was somewhat greater than the healthy controls $(31.8 \pm 1.1 \mathrm{vs}$. $25.8 \pm 0.55$ years $),(F[1,139]=24.3, p<0.001)$. Consequently, to avoid any false conclusions caused by an influence of age on the parameters studied, groups were adjusted for age by exclusion of the youngest $15 \%$ of healthy controls and the oldest $15 \%$ of patients [55].

Age adjustment was performed for analysis of antisaccade measures and PANSS scores, while between-group differences in genotypes were analyzed for all participants.

\section{Statistical analysis}

Statistical analysis of results was performed using STATISTICA 6.0 software. The Chi square test was used to evaluate the Hardy-Weinberg genotypic frequencies and the Fisher exact test was used to evaluate the proportion of different alleles of $r s 4680$ and $r s 3749034$ in healthy control $(\mathrm{CON})$ and schizophrenia patient $(\mathrm{SCH})$ groups.

Two-way ANOVA (General Linear Model procedure, GLM) was applied to study the effects of group, genotype and their interaction on the measures of the antisaccade task performance. Post hoc comparisons were performed using Student's t-test with Bonferroni correction for multiple comparisons. Spearman's correlations between PANSS scores and AS measures were analyzed separately for different $C O M T$ and $G A D 1$ genotypes.

\section{Results}

\section{Genotyping: distribution of COMT and GAD1 polymorphisms in control and schizophrenic patient groups}

\section{COMT rs 4680 polymorphism schizophrenic patient and control group distribution outcomes}

The distribution of the COMT genotype in the control group was within the Hardy-Weinberg equilibrium (Table 1). However, a significant deviation from the Hardy-Weinberg equilibrium equation was observed in the clinical patient group.

Comparison of genotype frequencies within the control group revealed that the proportion of $\mathrm{Val} / \mathrm{Met}$ heterozygotes was significantly higher than either Val homozygotes $(p=0.011)$ or Met homozygotes $(p=0.002)$. 
Table 1 Genotype frequencies of $r s 4680$ (COMT) and rs3749034 (GAD1) in the control (Con) and schizophrenic patient (Sch) groups

\begin{tabular}{|c|c|c|c|c|c|c|c|}
\hline \multirow[t]{2}{*}{ SNPs } & \multirow[t]{2}{*}{ Group } & \multicolumn{5}{|c|}{ Frequencies \% (n) } & \multirow[t]{2}{*}{$p\left(\chi^{2}\right)^{*}$} \\
\hline & & Alleles & & Genotypes & & & \\
\hline \multirow[t]{3}{*}{ rs 4680} & & Val & Met & $\mathrm{Val} / \mathrm{Val}$ & Val/Met & Met/Met & \\
\hline & $\operatorname{Sch}(n=78)$ & $43.0 \%(80)$ & $57.0 \%(106)$ & $32.0 \%(25)$ & $38.5 \%(30)$ & $29.4 \%(23)$ & $P=0.024\left(\chi^{2}=4.81\right)$ \\
\hline & Con $(n=63)$ & $51.6 \%(65)$ & $48.4 \%(61)$ & $27.0 \%$ & $49.2 \%(31)$ & $23.8 \%(15)$ & $P=0.125\left(\chi^{2}=2.35\right)$ \\
\hline \multirow[t]{3}{*}{ rs3749034 } & & $\mathrm{C}$ & $\mathrm{T}$ & $\mathrm{C} / \mathrm{C}$ & $\mathrm{C} / \mathrm{T}$ & $\mathrm{T} / \mathrm{T}$ & \\
\hline & $\operatorname{Sch}(n=78)$ & 73.1 (114)\# & $26.9(42)$ & $59.8 \%(42)$ & $38.5 \%(30)$ & $7.7 \%(6)$ & $P=0.365\left(\chi^{2}=0.81\right)$ \\
\hline & Con $(n=63)$ & $62.7 \%$ (79) & $37.3 \%(47)$ & $38.1 \%$ (24) & $49.2 \%(31)$ & $12.7 \%(8)$ & $P=0.680\left(\chi^{2}=0.17\right)$ \\
\hline
\end{tabular}

* $p$ deviation from the Hardy-Weinberg equilibrium distribution

$\# p<0.05$ relative to Con group

Alongside this, the relative proportions of various genotypes did not vary $(p>0.1)$ within the patient group.

\section{GAD1 rs3749034 polymorphism schizophrenic patient and control group distribution outcomes}

In both groups, the distribution of the GADl genotype was within the Hardy-Weinberg equilibrium (Table 1). The frequency of the $\mathrm{C}$ allele in the schizophrenic patient group was significantly higher than it was in the healthy controls ( $73.1 \%$ compared to $62.7 \%, p=0.038$ ).

\section{Absence of any age or educational level influence on COMT and GAD1 genotype distribution in schizophrenic patient and control groups}

After adjustment of groups for age and artifact rejection, 65 patients and 53 healthy subjects were included in the analysis of antisaccade measures and PANSS scores. The mean age in the control group was $26.4 \pm 1.1$ years and the mean age in the schizophrenic patient group was $27.1 \pm 1.3$ years $[F(1,116)=1.15, p=0.32]$. Demographic characteristics of included participants from both groups in relation to their COMT and GAD1 genotype are presented in Table 2. No significant age differences existed between COMT and $G A D 1$ genotypes in either the patient or control groups and no group x genotype interaction was observed $(F<1.18$,
Table 2 Demographic characteristics of heathy control subjects and schizophrenic patients (included in the antisaccade analysis) in relation to their total and COMT and GADl genotypes

\begin{tabular}{|c|c|c|c|c|}
\hline Parameters & Group & Polymorphism & Genotype & Mean \pm SEM \\
\hline \multirow[t]{10}{*}{ Age (years) } & \multirow[t]{5}{*}{ Healthy control $(n=53)$} & \multirow[t]{3}{*}{ rs4680 (COMT) } & Met/Met $(n=13)$ & $26.2 \pm 1.6$ \\
\hline & & & $\mathrm{Val} / \mathrm{Met}(n=26)$ & $25.9 \pm 1.4$ \\
\hline & & & $\mathrm{Val} / \mathrm{Val}(n=14)$ & $27.5 \pm 1.1$ \\
\hline & & \multirow[t]{2}{*}{ rs3749034 (GAD1) } & $\mathrm{C} / \mathrm{C}$ & $27.3 \pm 1.4$ \\
\hline & & & $\mathrm{C} / \mathrm{T}+\mathrm{T} / \mathrm{T}$ & $25.7 \pm 1.2$ \\
\hline & \multirow[t]{5}{*}{ Schizophrenia patients $(n=65)$} & \multirow[t]{3}{*}{ rs4680 (COMT) } & Met/Met $(n=20)$ & $25.8 \pm 1.4$ \\
\hline & & & $\mathrm{Val} / \mathrm{Met}(n=24)$ & $27.3 \pm 1.2$ \\
\hline & & & $\mathrm{Val} / \mathrm{Val}(n=21)$ & $28.6 \pm 1.8$ \\
\hline & & \multirow[t]{2}{*}{ rs3749034 (GAD1) } & $\mathrm{C} / \mathrm{C}$ & $27.1 \pm 1.0$ \\
\hline & & & $\mathrm{C} / \mathrm{T}+\mathrm{T} / \mathrm{T}$ & $26.8 \pm 1.4$ \\
\hline \multirow[t]{10}{*}{ Education (years) } & \multirow[t]{5}{*}{ Healthy control $(n=53)$} & \multirow[t]{3}{*}{$r s 4680(\mathrm{COMT})$} & Met/Met $(n=13)$ & $15.1 \pm 0.4$ \\
\hline & & & $\mathrm{Val} / \mathrm{Met}(n=26)$ & $14.6 \pm 0.3$ \\
\hline & & & $\mathrm{Val} / \mathrm{Val}(n=14)$ & $15.0 \pm 0.4$ \\
\hline & & \multirow[t]{2}{*}{ rs3749034 (GAD1) } & $\mathrm{C} / \mathrm{C}$ & 15.10 .5 \\
\hline & & & $\mathrm{C} / \mathrm{T}+\mathrm{T} / \mathrm{T}$ & 14.80 .3 \\
\hline & \multirow[t]{5}{*}{ Schizophrenia patients $(n=65)$} & \multirow[t]{3}{*}{ rs4680 (COMT) } & Met/Met $(n=20)$ & $11.2 \pm 0.3$ \\
\hline & & & $\mathrm{Val} / \mathrm{Met}(n=24)$ & $12.9 \pm 0.9$ \\
\hline & & & $\mathrm{Val} / \mathrm{Val}(n=21)$ & $12.3 \pm 0.6$ \\
\hline & & \multirow[t]{2}{*}{ rs3749034 (GAD1) } & $\mathrm{C} / \mathrm{C}$ & 13.00 .4 \\
\hline & & & $\mathrm{C} / \mathrm{T}+\mathrm{T} / \mathrm{T}$ & 11.80 .4 \\
\hline
\end{tabular}


$p>0.38$ ). Education level was significantly higher in the control group $(14.9 \pm 0.3$ years) relative to the schizophrenic group $(12.4 \pm 0.3$ years $)[F(1,116)=22.2, p<0.001]$. However, no effect of COMT or GADI genotype on education was observed, neither was there any group $\mathrm{x}$ genotype interaction $(F<1.6, p>0.21)$.

\section{PANSS scores for genotypes in schizophrenic patients}

The clinical characteristics of the patients across genotypes are presented in Table 3. ANOVA revealed a significant effect $[F(2,70)=3.84, p<0.05]$ of the COMT genotype on the General Psychopathology Scores (PANSS). The Val/ Val carriers had higher General Psychopathology Scores (PANSS) than either the Met/Met $(p=0.043)$ or Val/Met $(p=0.029)$ variants. Other effects of studied genotypes were insignificant.

\section{Genotypes and antisaccade task performance}

\section{COMT genotype and antisaccades}

To test the hypothesis that COMT Val158Met affected the measures of antisaccade task performance, a GLM ANOVA analysis was performed. There was no significant effect of

Table 3 Symptom ratings (PANSS; mean \pm SEM) in schizophrenic patients (included in the antisaccade analysis) in relation to their COMT and $G A D 1$ genotypes

\begin{tabular}{|c|c|c|c|c|}
\hline Sample & PANSS total score & PANSS positive score & $\begin{array}{l}\text { PANSS nega- } \\
\text { tive score }\end{array}$ & PANSS general score \\
\hline Total & $85.5 \pm 1.8$ & $19.4 \pm 0.7$ & $22.4 \pm 0.7$ & $43.9 \pm 1.0$ \\
\hline Carriers of the Met/Met variant of $\operatorname{COMT}(n=20)$ & $84.7 \pm 2.4$ & $19.3 \pm 1.2$ & $22.1 \pm 1.3$ & $42.9 \pm 1.7$ \\
\hline Carriers of the Val/Met variant of COMT $(n=24)$ & $82.0 \pm 2.9$ & $18.1 \pm 1.2$ & $22.1 \pm 1.4$ & $42.1 \pm 1.8$ \\
\hline Carriers of the Val/Val variant of $\operatorname{COMT}(n=21)$ & $91.2 \pm 3.5$ & $21.1 \pm 1.4$ & $22.6 \pm 1.4$ & $47.9 \pm 2.0^{*} \#$ \\
\hline Carriers of the $\mathrm{C} / \mathrm{C}$ variant of $G A D 1(n=34)$ & $87.1 \pm 2.2$ & $19.8 \pm 0.9$ & $23.3 \pm 0.9$ & $44.0 \pm 1.2$ \\
\hline Carriers of the T allele of $G A D 1(n=31)$ & $83.8 \pm 2.0$ & $19.4 \pm 0.9$ & $21.6 \pm 0.9$ & $43.8 \pm 1.2$ \\
\hline
\end{tabular}

$* p<0.05$ relative to carriers of the Val/Met variant of COMT

$\# p<0.05$ relative to carriers of the Met/Met variant of COMT
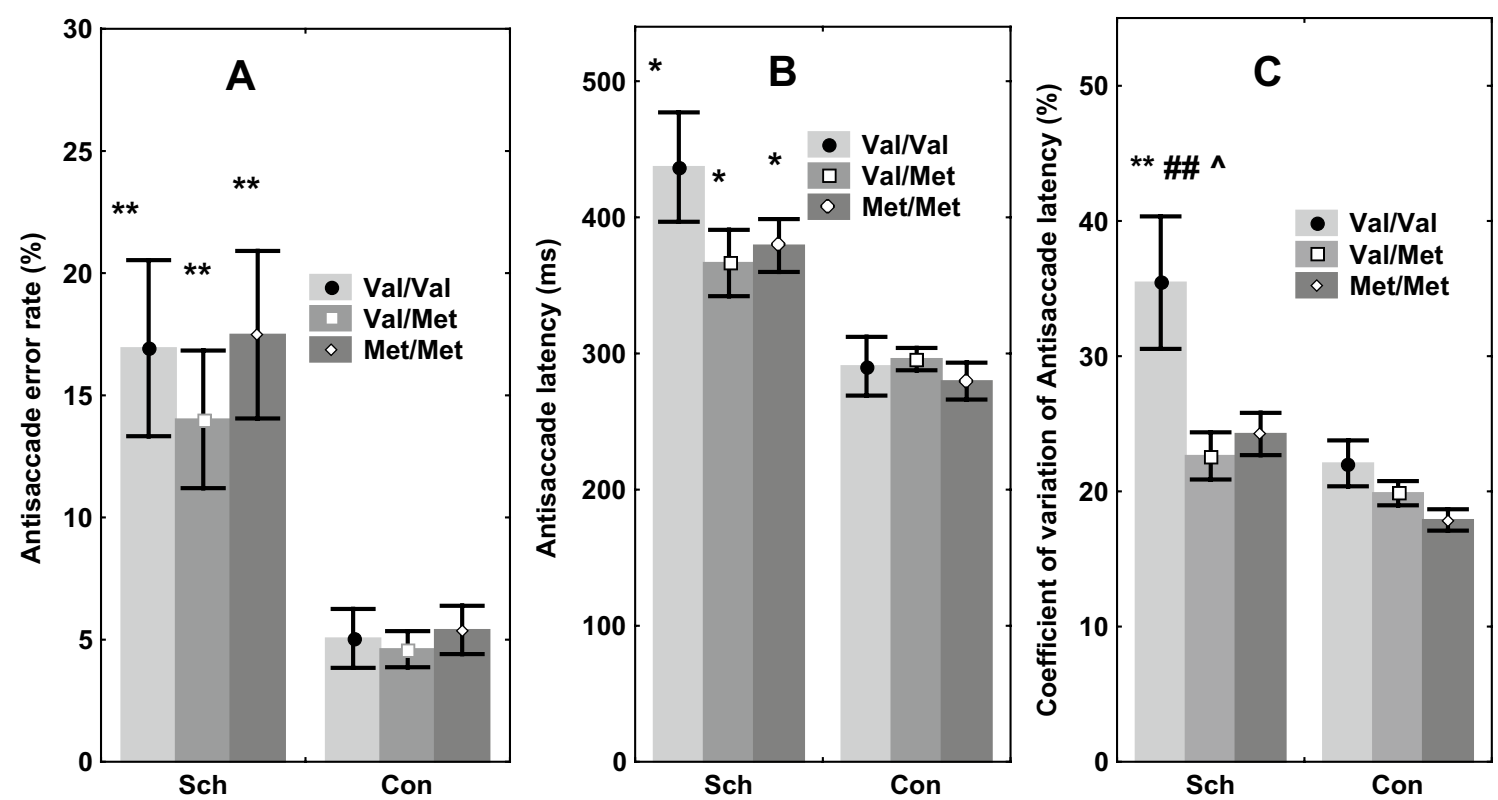

Fig. 2 The effects of COMT Val158Met polymorphism on antisaccade parameters in schizophrenic patients (Sch) and healthy controls (Con). a Antisaccade error rate $(\%), * * p<0.01$ relative to the carriers of the same COMT genotype from the Con group. b Antisaccade latency $(\mathrm{ms}), * p<0.05$ relative to the carriers of the same COMT genotype from the Con group. c Coefficient of variation of antisaccade latency, $(\%) .{ }^{* *} p<0.01$ relative to the carriers of the $\mathrm{Val} / \mathrm{Val}$ COMT genotype from the Con group, ${ }^{\# \#} p<0.01$ relative to $\mathrm{Val} / \mathrm{Met}$ carriers from the Sch group, ${ }^{\wedge} p<0.05$ relative to Met/Met carriers from Sch group 
genotype on the error rate $[F(2,114)=0.41, p=0.6]$ in the pooled sample of patients and controls. In addition, no genotype $\mathrm{x}$ diagnosis interaction was exposed $[F(1,2$, $112)=0.389, p=0.678]$, though there was a highly significant effect of diagnosis on the error rate $[F(1,116)=19.02$, $p=0.00004$ ] (Fig. 2a).

Additionally, comparison of Val carriers (Val/Val + Val/ Met genotypes) versus Met homozygotes, or Met carriers (Met/Met + Val/Met genotypes) versus Val homozygotes did not disclose any association between COMT genotype and error rate.

Similar outcomes were obtained for the latency of correct saccades. Hence, there was neither a significant effect of genotype $[F(2,114)=0.98, p=0.39]$ nor any interaction between genotype $\mathrm{x}$ diagnosis. Nevertheless, the effect of diagnosis on saccade latency was once again highly significant $[F(1,116)=18.6, p<0.001]$, although comparison of Val carriers versus Met homozygotes, or Met carriers versus Val homozygotes did not divulge any influence of COMT genotypes on saccade latency (Fig. 2b).

In relation to the coefficient of variation $(\mathrm{CV})$ for the latency of correct saccades, a significant effect of genotype $[F(2,114)=6.1, p<0.01]$ was disclosed in the pooled sample of patients and controls. No significant genotype $\mathrm{x}$ diagnosis interaction was recorded $[F(1,2,112)=2.41$, $\mathrm{p}=0.076]$. However, the effect of diagnosis on saccades was highly significant $[F(1,116)=18.2, p<0.0001]$ (Fig. 2c).

Furthermore, in the patient group, post hoc $t$ test analysis with Bonferroni correction for multiple comparisons unveiled a substantially increased CV in the Val homozygote sample compared to either Val/Met heterozygotes $(p=0.009)$ or Met homozygotes $(p=0.015)$. On the other hand, there was no effect of COMT genotype on the $\mathrm{CV}$ in the control group $(p>0.21)$.

Analysis of CV differences between the samples of Val homozygotes and Met carriers also revealed significant effects for genotype $[F(2,114)=12.3, p=0.001]$, genotype $\mathrm{x}$ diagnosis interaction $[\mathrm{F}(1,2,112)=5.11, \mathrm{p}=0.021]$ and diagnosis alone $[F(1,116)=20.4, p<0.001]$ in the pooled sample. Post hoc comparisons showed distinctly increased $\mathrm{CV}$ in the Val homozygotes compared to Met carriers in the patient group $(p=0.0005)$, but not in the controls $(p=0.68)$.

\section{GAD1 genotype and antisaccades}

Data from 65 patients ( $34 \mathrm{C}$ homozygotes, $25 \mathrm{C} / \mathrm{T}$ heterozygotes and $6 \mathrm{~T}$ homozygotes) in addition to 53 healthy subjects ( $22 \mathrm{C}$ homozygotes, $24 \mathrm{C} / \mathrm{T}$ heterozygotes and $7 \mathrm{~T}$ homozygotes) were included in the analysis of antisaccade measures. Due to the low number of $\mathrm{T}$ homozygotes, combined samples of $\mathrm{T}$ allele carriers $(\mathrm{C} / \mathrm{T}+\mathrm{TT}$ genotypes) and $\mathrm{C}$ homozygotes were compared.
In the case of the error rate, significant effects of genotype $[F(1,116)=5.41, p=0.023]$ and diagnosis $[F(1$, $116)=15.23, p<0.001]$ were observed. Also, post hoc comparisons revealed that mean values of error rate were higher in $\mathrm{T}$ carriers compared to $\mathrm{C}$ homozygotes, and the differences were significant for the patient group $(p=0.023)$, but not for the healthy controls ( $p=0.65$ ) (Fig. 3a).

Statistically significant effects of genotype $[F(1$, $116)=4.10, p=0.020]$, diagnosis $[F(1,116)=24.87$, $p<0.001]$, and genotype $\mathrm{x}$ diagnosis interactions $[F(1,1$, $114)=8.94, p<0.01]$ were observed to the latency of correct saccades. Additionally, post hoc comparison of means confirmed an increased saccade latency in $\mathrm{C}$ homozygotes compared to $\mathrm{T}$ allele carriers in the patient group $(p<0.001)$. In the control group, however, the effect of the GADl genotype was not significant $(p=0.82)$ (Fig. 3b).

The coefficient of variation for the latency of correct saccades was not dependent on the genotype $[F(1,116)=0.16$, $p=0.84]$, although an effect of group $[F(1,116)=11.04$, $p<0.01]$ but not a group $\mathrm{x}$ genotype interaction $[F(1,1$, $113)=0.38, p=0.69$ ] was observed (Fig. 3c).

\section{Predictive logit-models with antisaccades}

Overall, the results demonstrated that patients differed from controls in their error rate, antisaccade latency and coefficient of variation within the latencies for correct saccades. Subsequently, whether these measures could serve as predictors for group differentiation was evaluated using binary logistic regression, where group ( $y=0$ for healthy controls and $y=1$ for schizophrenic patients) was taken as a dependent variable for different COMT and GAD1 genotypes. This approach was fruitful only in the case of the GADl genotypes.

\section{Logit-regression analysis with variants of the GAD1 genotype}

The between-group difference in antisaccade latency was significant only in carriers of the CC variant of $r s 3749034$. A comparison was then made between the predictive validities of the logistic regression model in the total sample, CC carriers and $\mathrm{CT}+\mathrm{TT}$ carriers. Three equations were generated by STATISTICA 6.0 (Table 4), where $\boldsymbol{y}$ was the probability of the tested person attribution to the schizophrenic patient group and three sets of predictors (error rate, saccade latency and $\mathrm{CV}$ ) were used as arguments.

A relatively high level of specificity of correctly identified healthy subjects (90-100\%) was observed in all three samples. At the same time, the sensitivities (correctly identified patients) of models in the total sample and in the CT + TT sample were comparatively low (67.7 and 48.4\% 

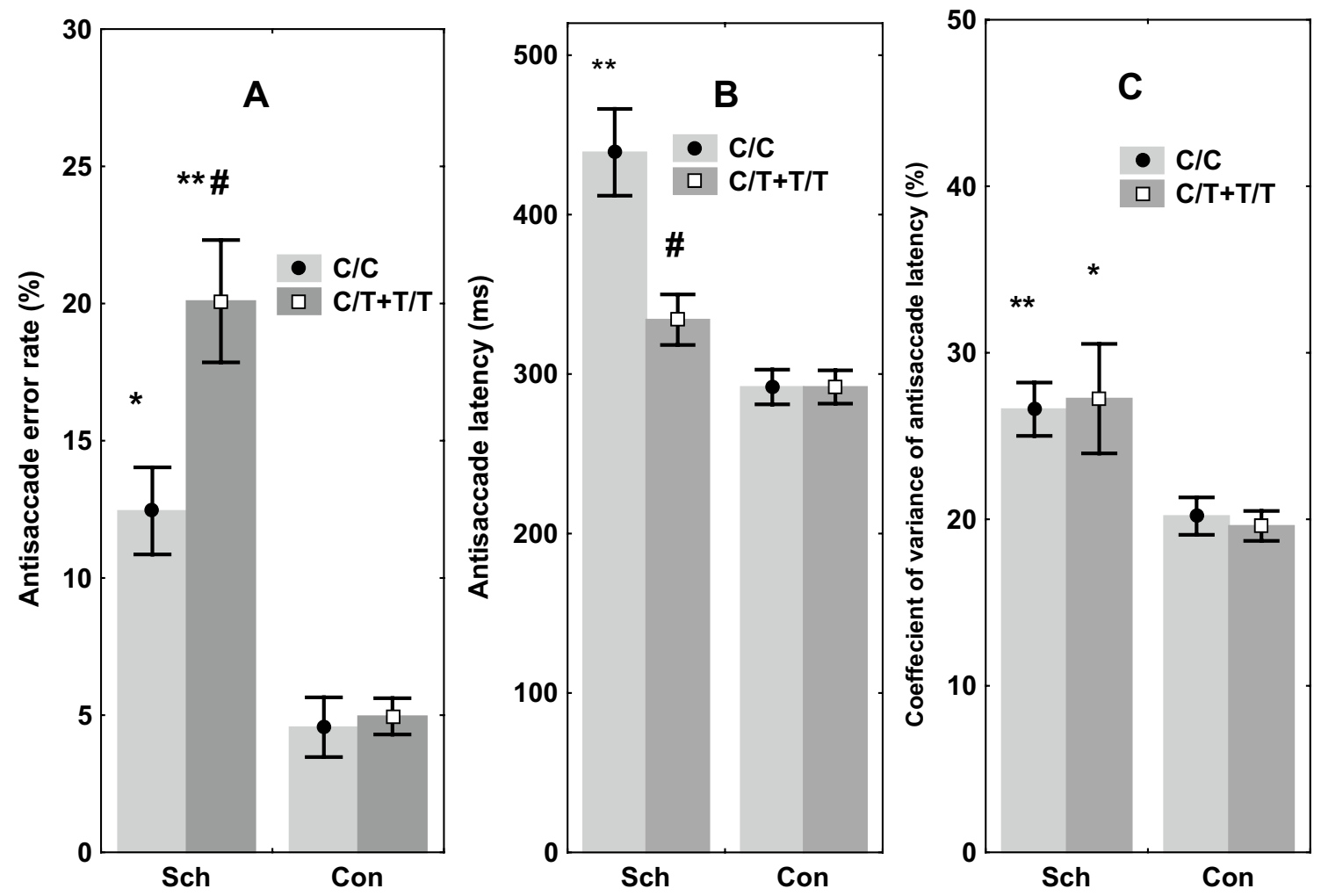

Fig. 3 The effects of $r s 3749034$ polymorphism of GAD1 on antisaccade parameters in schizophrenic patients $(\mathrm{Sch})$ and healthy controls (Con). a Error rate, \%. ${ }^{*} p<0.05, * * p<0.01$ relative to the carriers of the same genotype from the Con group, ${ }^{\#} p<0.05$ relative to the carriers of the $\mathrm{C} / \mathrm{C}$ genotype from Sch group, b Latency, ms. ${ }^{* *} p<0.01$ relative to the cariers of $\mathrm{C} / \mathrm{C}$ genotype from Con group, ${ }^{*} p<0.05$ relative to the carriers of $\mathrm{C} / \mathrm{C}$ genotype from Sch group. $\mathbf{c}$ Coefficient of variation of antisaccade latency, $\%$. $* p<0.05, * * p<0.01$ relative to the carriers of the same genotype from the Con group

Table 4 Results of logit analysis with error rate, latency and latency variability (CV) for correct saccades as predictors for differentiation of healthy subjects and schizophrenic patients in the total sample and in the samples with different genotypes of GAD1

\begin{tabular}{lllll}
\hline Samples & Model quality & $\begin{array}{l}\text { Specificity (correctly identi- } \\
\text { fied healthy subjects, } \%)\end{array}$ & $\begin{array}{l}\text { Sensitivity (correctly } \\
\text { identified patients, \%) }\end{array}$ & $\begin{array}{l}\text { Accuracy (correctly classified par- } \\
\text { ticipants in the total sample, \%) }\end{array}$ \\
\hline Total & $\begin{array}{l}\chi^{2}=47.2 \\
p<0.0001\end{array}$ & $90.6(48$ of 53$)$ & $67.7(44$ of 65$)$ & $78.0(92$ of 118$)$ \\
CC carriers & $\begin{array}{l}\chi^{2}=26.8 \\
p<0.0001\end{array}$ & $90.9(20$ of 22$)$ & $91.2(31$ of 34$)$ & $91.1(51$ of 56$)$ \\
CT + TT carriers & $\begin{array}{l}\chi^{2}=27.2 \\
p=0.0010\end{array}$ & $100 \%(31$ of 31$)$ & $48.4(15$ of 34$)$ & 74.846 of 65 \\
\hline
\end{tabular}

respectively), whereas in the sample of CC carriers, the sensitivity of the model was high $(91.2 \%)$.

\section{Correlations between antisaccade measures and PANSS scores}

\section{Correlations within the total sample}

In the total patient sample, 9 significant correlations were found. Analysis revealed that as a whole, impaired AS performance correlated with increased PANSS scores (Table 5). Error rate correlated positively with P6 (suspiciousness/persecution), N5 (difficulty in abstract thinking) and $\mathrm{O} 10$ (disorientation) scales. AS latency correlated positively with N1 (blunted affect), N5, N6 (lack of spontaneity and flow of conversation), and $\mathrm{O} 7$ (motor retardation) scales, but negatively with the P4 scale (hyperactivity), and latency variability correlated positively with the N2 scale (emotional withdrawal). 
Table 5 Correlations between antisaccade measures and PANSS scores in the total sample of patients carrying different COMT or GAD1 genotypes

\begin{tabular}{|c|c|c|c|c|c|c|c|c|c|c|c|}
\hline & \multirow[t]{3}{*}{ PANSS } & \multirow{2}{*}{\multicolumn{2}{|c|}{$\begin{array}{l}\text { Total sample } \\
n=65\end{array}$}} & \multicolumn{4}{|l|}{ COMT } & \multicolumn{4}{|l|}{$G A D 1$} \\
\hline & & & & \multicolumn{2}{|c|}{$\begin{array}{l}\text { Met/Met + Val/ } \\
\text { Met } \\
n=44\end{array}$} & \multicolumn{2}{|l|}{$\begin{array}{l}\text { Val/Val } \\
n=21\end{array}$} & \multicolumn{2}{|l|}{$\begin{array}{l}\mathrm{CC} \\
n=34\end{array}$} & \multicolumn{2}{|l|}{$\begin{array}{l}n=31 \\
\mathrm{CT}+\mathrm{TT}\end{array}$} \\
\hline & & $r$ & $p$ & $r$ & $p$ & $r$ & $p$ & $r$ & $p$ & $r$ & $p$ \\
\hline \multirow[t]{4}{*}{ Error rate } & P1 delusions & 0.24 & 0.11 & 0.31 & 0.25 & 0.42 & 0.10 & 0.47 & 0.026 & 0.02 & 0.93 \\
\hline & P6 suspiciousness/persecution & 0.46 & 0.001 & 0.32 & 0.12 & 0.73 & 0.002 & 0.53 & 0.011 & 0.42 & 0.042 \\
\hline & N5 difficulty in abstract thinking & 0.30 & 0.046 & 0.25 & 0.27 & 0.67 & 0.006 & 0.24 & 0.27 & 0.36 & 0.085 \\
\hline & O10 disorientation & 0.35 & 0.031 & 0.31 & 0.049 & 0.44 & 0.049 & 0.20 & 0.37 & 0.42 & 0.041 \\
\hline \multirow[t]{5}{*}{ Latency } & P4 hyperactivity & 0.32 & 0.031 & -0.15 & 0.51 & -0.69 & 0.006 & -0.15 & 0.48 & -0.61 & 0.002 \\
\hline & N1 blunted affect & 0.31 & 0.053 & 0.23 & 0.11 & 0.39 & 0.20 & 0.16 & 0.47 & 0.47 & 0.021 \\
\hline & N5 difficulty in abstract thinking & 0.32 & 0.049 & 0.40 & 0.026 & -0.08 & 0.75 & 0.11 & 0.63 & 0.39 & $\mathbf{0 . 0 3 8}$ \\
\hline & $\begin{array}{l}\text { N6 lack of spontaneity and flow of } \\
\text { conversation }\end{array}$ & $\mathbf{0 . 3 3}$ & 0.024 & 0.21 & 0.27 & 0.64 & 0.011 & -0.15 & 0.50 & 0.32 & 0.13 \\
\hline & O7 motor retardation & 0.45 & 0.002 & 0.34 & 0.043 & 0.69 & 0.005 & 0.44 & 0.043 & 0.46 & 0.023 \\
\hline $\mathrm{CV}$ & N2 Emotional withdrawal & 0.33 & 0.027 & 0.23 & 0.21 & 0.51 & 0.036 & 0.25 & 0.25 & 0.38 & 0.11 \\
\hline
\end{tabular}

All values in bold text are significant $(p<0.05)$

$\mathrm{CV}$, coefficient of variation

\section{Variants of the COMT genotype}

In the case of Val homozygotes, correlations between AS measures and PANSS scores were very similar to those for the total sample, and only the correlation between AS latency and N5 scale was insignificant. In contrast, within the sample of Met carriers, only 3 correlations were significant. These were between error rate and O10, AS latency and N5, along with AS latency and the $\mathrm{O} 7$ score (Table 5).

\section{Variants of the GAD1 genotype}

In the sample of $\mathrm{T}$ carriers, 6 significant correlations were detected. In comparison with the total sample, one new association between AS latency and blunted affect (N1) was unmasked, whilst 3 correlations from the total sample were insignificant (Table 4). Within the sample of C homozygotes, only 3 correlations were significant, namely, error rate which correlated positively with P1 (delusions), P6 scores (lack of spontaneity and flow of conversation), in addition to AS latency which correlated positively with $\mathrm{O} 7$ score (motor retardation).

In conclusion, error rate correlated predominantly with positive scales (P1, P6) and disorientation (O10). Latency correlated positively with negative scales (N1, N5, N6) and motor retardation (O7), and negatively with P4 (hyperactivity). Both error rate and AS latency correlated with difficulty in abstract thinking (N5) and only one positive correlation between latency variability (CV) and emotional withdrawal (N2) was obtained. The largest number of significant correlations was obtained for Val homozygotes (rs4680) and T carrier (rs3749034) samples.

\section{Discussion}

A possible association between COMT Val158Met and GAD1 rs3749034 polymorphisms with antisaccade task (AS) performance was investigated in schizophrenic patients. In summary, the following principal findings were obtained: (1) genotyping revealed a decreased frequency of Val/Met heterozygotes in COMT rs4680 polymorphism and an increased frequency of $\mathrm{C}$ allele carriers in $G A D 1$ rs3749034 polymorphism in patients compared to controls; (2) AS performance was impaired in schizophrenic patients versus controls, whereby patients displayed elevated error rates, and increased response latencies as well as latency variability (coefficient of variation) of correct responses compared to controls; (3) the polymorphisms in question were associated with the AS performance modifications in patients but not controls; (4) In the case of the COMT rs 4680 polymorphism, an augmented latency variability was observed in Val homozygotes compared to Met allele carriers in patients; (5) for the GAD1 rs3749034 polymorphism, an elevated error rate was found in $\mathrm{T}$ carriers relative to $\mathrm{C}$ homozygotes, although an increased 


\section{Schizophrenic patient polymorphisms}

$\downarrow-$ Val/Met heterozygotes in COMT - (rs4680)

$\uparrow$ - C allele carriers in GAD1 - (rs3749034)

1

Association

7

Impaired Antisaccade Performance

$\uparrow$-Error rate $\uparrow$ - Latency $\uparrow$-Latency Variability

COMT (rs4680)

$\uparrow$ - Latency Variability in Val homozygotes - vs - Met allele carriers

GAD1 (rs3749034)

$\uparrow \quad \uparrow$ - Error Rate in T carriers - vs - $C$ homozygotes

$\uparrow$ - Latency of Correct Responses in C homozygotes - vs - T carriers

Fig. 4 Scheme summarizing the principal findings

latency of correct responses was noted in $\mathrm{C}$ homozygotes relative to $\mathrm{T}$ carriers (Fig. 4).

\section{COMT Val158Met polymorphism and antisaccade performance}

The finding that there was a lower frequency of Val/Met heterozygote carriers among schizophrenic patients compared to healthy subjects coincides with that of Hoenicka et al., [56]. The result also accords with the outcome of the metaanalysis performed by Costas et al., [57], in which a deficit of $r s 4680$ heterozygotes among male schizophrenic patients suggested a protective effect for heterozygosis. The current data also concur with the notion that an inverted U-shaped relationship in dopamine signaling at the molecular level in the dorsolateral prefrontal cortex arises from optimal levels of gene product in COMT Val/Met heterozygote carriers.

Analysis of the outcome of COMT rs 4680 polymorphism on AS performance divulged an increased coefficient of variation of latency (CV) for correct saccades in Val homozygotes compared to Met carriers in the pooled samples of patients and controls and in the patient group.

This increased antisaccade latency variability in schizophrenic patients corroborates previously reported studies involving not only schizophrenic patients, but also individuals with schizotypal traits $[29,58,59]$. A specific increase in latency variability but not mean latency of visually driven saccades in schizophrenic patients prompted the hypothesis that this deficit may originate from a distinct frontal cortical aberration in schizophrenia [58-60]. In non-human primates, the response latency in saccadic tasks correlates with the rise time of neuronal activity between the resting state and a threshold level in the frontal eye field (FEF) [61]. Thus, in extrapolating to schizophrenic patients, any increased latency variability may well have been related to a primary increased variability in neuronal activity rise time.

Considering the postulation that the COMT Val allele is associated with increased dopamine inactivation, this might conceivably result in reduced dopamine neurotransmission and a somewhat compromised prefrontal cortical function. It is, therefore, speculated that alterations in the fine-tuning of cortical DA-ergic pathways may be responsible for abnormal (disorganized) neuronal activity and a decreased signal/noise ratio in the prefrontal cortex would in turn lead to increased latency variability in the AS task.

In our study, the impact of COMT rs 4680 polymorphism on the clinical symptomatology of schizophrenia has also been exposed. Hence, a higher General Psychopathology Score and twice as many correlations between AS performance measures and PANSS scores were unveiled in Valcompared to Met-homozygotes.

Only in the Val homozygote sample did CV exhibit a positive correlation with N2 score (emotional withdrawal), while the only distinctive correlation in the sample of Met allele carriers was a positive association between AS latency and N5 scale (Difficulty in abstract thinking). These results are compatible with the data obtained by others who reported that the presence of the Val allele was positively associated with prefrontal activation during emotional processing, while the Met allele was associated with greater prefrontal activation during cognitive processing [37].

Despite there being a selection of findings to date, a range of investigations have generally identified inferior performance in tests of executive cognition associated with the COMT Val allele. Furthermore, associations between the COMT rs 4680 polymorphism and endophenotypes are consistently more evident in schizophrenic patients than in healthy controls [11]. It has also emerged that reduced volumes of frontal brain areas are associated with the Val/ Val genotype in schizophrenic patients [39] as well as individuals at high risk of psychosis [38]. Meanwhile, there are divergent reports concerning the impact of COMT rs 4680 polymorphism on antisaccade performance. In this context, a larger number of Val158 alleles have been associated ostensibly with briefer and less variable AS latencies in schizophrenic patients [29], whilst others have shown an absence of any association between $r s 4680$ polymorphism and AS performance [27, 30]. The results discrepancies between previous reports and our study may have been derived from methodological differences. Essentially, the experimental paradigm of Haraldsson and coworkers, [29] for example, was more complex (4 peripheral locations) and no training session was employed. Consequently, even the control subjects in their study expressed considerably more errors (19-36\%) than in our study (4.8\%). Other differences are related to the participant samples, since both men and women participated in both cited studies, handedness was 
not considered, and patients were on stable treatments. Conversely, in our study, all subjects were right-handed males, and all of the patients were not under treatment. Data regarding the selective action of genes or gene-trait interactions have accumulated in recent years [52]. In fact, trait-relevant genes have different effects in respect of gender, psychological traits and other inherited or acquired individual characteristics. Thus, a more homogeneous sample of subjects inevitably facilitates detection of specific genetic effects.

\section{GAD1 rs3749034 polymorphism and antisaccade performance}

This is a preliminary report regarding the effects of GADI rs3749034 polymorphism on antisaccade performance. Subsequent analysis of the frequency of different variants of the $r s 3749034$ polymorphism exposed a higher frequency of CC carriers in the schizophrenic patient group compared to healthy controls. This finding is in agreement with data obtained by some researchers [48, 49], but it is in contrast with the results of others [51]. Sources of these discrepancies, including such factors as the contribution of gender or ethnicity, are yet to be resolved. Nonetheless, it is noteworthy that we identified a deleterious effect of $r s 3749034$ on antisaccade performance only in schizophrenic patients, just as we observed in the case of the diminished performance with the Val158Met homozygotes (Fig. 4). Analysis of AS performance measures between samples revealed that the error rate was higher in T carriers, but AS latency was increased in $\mathrm{CC}$ homozygotes. Moreover, an increase in the latencies relative to control levels was found only in CC homozygotes. The correlation pattern between antisaccade measures and PANSS scores included predominantly negative ratings in $\mathrm{T}$ carriers, and positive scores in $\mathrm{CC}$ carriers. Also, there were considerably more correlations for $\mathrm{T}$ carriers.

Error rate in the AS task is one of the most compelling candidates for a schizophrenia endophenotype and numerous studies have consistently reported a greater number of inappropriate reflexive saccades to the target in different populations of schizophrenia patients $[12,26]$. Increased error rate in patients is also thought to be associated with an impaired ability to inhibit intrinsic responses to redundant or irrelevant inputs [26].

Concerning the antisaccade response latency, most studies also report protracted latencies for correct antisaccades in patients with schizophrenia compared to controls [12, 22, $26,62]$. It is well-known that in healthy subjects, antisaccade response latencies are more prolonged than prosaccades and this can be attributed to additional cognitive processes that are invoked to perform the AS task correctly. Empirically, antisaccades entail an aptitude to restrain a reflexive stimulus-driven prosaccade to a peripheral visual target, then to achieve a coordinated transformation and initiate a voluntary oculomotor response towards the opposite side to the target [14]. On the other hand, studies of visually guided saccades in schizophrenia have reported both a prominence of anticipatory saccades as well as bimodal patient latencies which are either slower or match those of healthy controls [63, 64]. It has, therefore, been proposed that a deficit in prefrontal cortical processes in relation to the oculomotor system is associated with a predisposition to schizophrenia [65].

In this connection, the genotype carried by $r s 3749034$ patients is likely to determine prefrontal cortical insufficiency and any ensuing impaired AS task performance inherent in schizophrenia. In addition, genotypic variations in GADl generally, may well modify cognitive function and conceivably related adverse changes in brain structure allometry. The elevated error rate in the AS task disclosed by $\mathrm{T}$ carriers is among the most typical disordered paradigms in schizophrenia $[12,26]$. Therefore, although the T-allele has a protective function in healthy subjects, this genotype might contribute to the poor performance of frontally mediated cognitive tasks and the occurrence of associated negative symptoms in patients with schizophrenia. This deduction also coincides with the proposition that both variants of rs3749034 can play their own specific roles in the pathological processes [51].

\section{Gene $\mathbf{x}$ trait interaction in schizophrenic patients}

An interaction of genotype and diagnosis was found not only for $r s 4680$, but also to a large degree for $r s 3749034$. So, the effects of both polymorphisms were observed principally in patients but not in healthy controls. This is evidence of the polygenic nature of schizophrenia and a major role of epistatic interaction in the development of the disease and its symptomatology.

This gene $\mathrm{x}$ trait interaction may be useful in the development of diagnostic tools, and in the present investigation, it has been shown that the selective use of AS evaluation in the sample of CC carriers substantially improved the quality of the diagnostic model. This approach was applied in our previous investigation where the Met/Met variant of $r s 4680$ was explored with respect to the risk of schizophrenia [66]. The development of a complex model that includes a number of genes and different relevant neurophysiological tests is the focus of future studies.

Further investigations in this direction warrant larger samples that will allow application of factor analysis to assess the effects of the studied polymorphisms on the behavioral control and mechanisms of psychopathology.

Acknowledgements The authors wish to thank Russian Foundation for Basic Research (RFBR), Department of Humanities and Social Sciences (project 16-06-00117) for funding this study. 
Author contributions Study concept and design - AVK, ZIS. AVK also wrote the antisaccade protocol for antisaccade recording and analysis. ZIS wrote the protocol for genotyping. Data acquisition AVK, ZIS. Data analysis - AVK, ZIS, MAG, RDES. Interpretation of data - AVK, ZIS, MAG, RDES. Drafted the manuscript - AVK, ZIS, MAG, RDES. Revised the manuscript for important intellectual content - AVK, ZIS, MAG, RDES. All authors have contributed to and have approved the final manuscript.

Funding Funding for this study was provided by the Russian Foundation for Basic Research (RFBR), Department of Humanities and Social Sciences (project 16-06-00117). The RFBR had no further role in study design; in the collection, analysis and interpretation of data; in the writing of the report; and in the decision to submit the paper for publication.

\section{Compliance with ethical standards}

Conflict of interest The authors declare that they have no conflicts of interest.

Open Access This article is distributed under the terms of the Creative Commons Attribution 4.0 International License (http://creativeco mmons.org/licenses/by/4.0/), which permits unrestricted use, distribution, and reproduction in any medium, provided you give appropriate credit to the original author(s) and the source, provide a link to the Creative Commons license, and indicate if changes were made.

\section{References}

1. Weinberger DR, Egan MF, Bertolino A, Callicott JH, Mattay VS, Lipska BK, Berman KF, Goldberg TE (2001) Prefrontal neurons and the genetics of schizophrenia. Biol Psychiatry 50:825-844. https://doi.org/10.1016/S0006-3223(01)01252-5

2. Manoach DS (2003) Prefrontal cortex dysfunction during working memory performance in schizophrenia: reconciling discrepant findings. Schizophr Res 60:285-298. https://doi.org/10.1016/ S0920-9964(02)00294-3

3. Eisenberg DP, Berman KF (2010) Executive function, neural circuitry, and genetic mechanisms in schizophrenia. Neuropsychopharmacol 35:258-277. https://doi.org/10.1038/npp.2009.111

4. Goldman-Rakic S (1999) The physiological approach: functional architecture of working memory and disordered cognition in schizophrenia. Biol Psychiatry 46:650-661. https://doi. org/10.1016/S0006-3223(99)00130-4

5. Tan H-Y, Callicott JH, Weinberger DR (2009) Prefrontal cognitive systems in schizophrenia: towards human genetic brain mechanisms. Cogn Neuropsychiatry 14:277-298. https://doi. org/10.1080/13546800903091665

6. Cannon TD, Huttunen MO, Lonnqvist J, Tuulio-Henriksson A, Pirkola T, Glahn D, Finkelstein J, Hietanen M, Kaprio J, Koskenvuo M (2000) The inheritance of neuropsychological dysfunction in twins discordant for schizophrenia. Am J Hum Genet 67:369382. https://doi.org/10.1086/303006

7. Toulopoulou T, Picchioni M, Rijsdijk F, Hua-Hall M, Ettinger U, Sham P, Murray R (2007) Substantial genetic overlap between neurocognition and schizophrenia: genetic modeling in twin samples. Arch Gen Psychiatry 64:1348-1355. https://doi.org/10.1001/ archpsyc.64.12.1348
8. Gottesman I, Gould T (2003) The endophenotype concept in psychiatry: etymology and strategic intentions. Am J Psychiatry 160:636-645. https://doi.org/10.1176/appi.ajp.160.4.636

9. Meyer-Lindenberg A, Weinberger DR (2006) Intermediate phenotypes and genetic mechanisms of psychiatric disorders. Nat Rev Neurosci 7:818-827. https://doi.org/10.1038/nrn1993

10. Tan H-Y, Callicot JH, Weinberger DR (2008) Intermediate phenotypes in schizophrenia genetics redux: is it a no brainer? Mol Psychiatry 13:233-238. https://doi.org/10.1038/sj.mp.4002145

11. Ira E, Zanoni M, Ruggeri M, Dazzan P, Tosato S (2013) COMT, neuropsychological function and brain structure in schizophrenia: a systematic review and neurobiological interpretation. J Psychiatry Neurosci 38:366-380. https://doi.org/10.1503/jpn.120178

12. Hutton SB, Ettinger U (2006) The antisaccade task as a research tool in psychopathology: a critical review. Psychophysiology 43:302-313. https://doi.org/10.1111/j.1469-8986.2006.00403.x

13. Broerse A, Crawford TJ, den Boer JA (2001) Parsing cognition in schizophrenia using saccadic eye movements: a selective overview. Neuropsychologia 39:742-756. https://doi.org/10.1016/ S0028-3932(00)00155-X

14. Levy DL, Mendell NR, Holzman PS (2004) The antisaccade task and neuropsychological tests of prefrontal cortical integrity in schizophrenia: empirical findings and interpretative considerations. World Psychiatry 3:32-40

15. Doricchi F, Perani D, Incoccia C, Grassi F, Cappa SF, Bettinardi V, Galati G, Pizzamiglio L, Fazio F (1997) Neural control of fastregular saccades and antisaccades: an investigation using positron emission tomography. Exp Brain Res 116:50-62. https://doi. org/10.1007/PL00005744

16. Curtis CE, D'Esposito M (2003) Success and failure suppressing reflexive behavior. J Cogn Neurosci 15:409-418. https://doi. org/10.1162/089892903321593126

17. Brown MR, Vilis T, Everling S (2007) Frontoparietal activation with preparation for antisaccades. J Neurophysiol 98:1751-1762. https://doi.org/10.1152/jn.00460.2007

18. O'Driscoll GA, Alpert NM, Matthysse SW, Levy DL, Rauch SL, Holzman PS (1995) Functional neuroanatomy of antisaccade eye movements investigated with positron emission tomography. Proc Natl Acad Sci USA 92, 925-929

19. McDowell JE, Dyckman KA, Austin BP, Clementz BA (2008) Neurophysiology and neuroanatomy of reflexive and volitional saccades: evidence from studies of humans. Brain Cogn 68:255270. https://doi.org/10.1016/j.bandc.2008.08.016

20. Everling S, Krappmann P, Flohr H (1997) Cortical potentials preceding pro- and antisaccades in man. Electroencephalogr. Clin Neurophysiol 102:356-362. https://doi.org/10.1016/S0013 -4694(96)96569-4

21. Klein C, Heinks T, Andresen B, Berg P, Moritz S (2000) Impaired modulation of the saccadic contingent negative variation preceeding antisaccades in schizophrenia. Biol Psychiatry 47:978-990. https://doi.org/10.1016/S0006-3223(00)00234-1

22. Kirenskaya AV, Myamlin VV, Novototsky-Vlasov VY, Pletnikov MV, Kozlovskaya IB (2011) The contingent negative variation laterality and dynamics in antisaccade task in normal and unmedicated schizophrenic subjects. Span J Psychol 14:869-883. https:// doi.org/10.5209/rev_SJOP.2011.v14.n2.34

23. Amador N, Schlag-Rey M, Schlag J (2004) Primate antisaccade. II. Supplementary eye field neuronal activity predicts correct performance. J Neurophysiol 91(4):1672-1689. https://doi. org/10.1152/jn.00138.2003

24. Johnston K, Everling S (2008) Neurophysiology and neuroanatomy of reflexive and voluntary saccades in nonhuman primates. Brain Cogn 68:271-283. https://doi.org/10.1016/j.bandc .2008 .08017 
25. Schlag-Rey M, Amador N, Sanchez H, Schlag J (1997) Antisaccade performance predicted by neuronal activity in the supplementary eye field. Nature 390(6658):398-401

26. Turetsky BI, Calkins ME, Light GA, Olincy A, Radant AD, Swerdlow NR (2007) Neurophysiological endophenotypes of schizophrenia: the viability of selected candidate measures. Schizophr Bull 33:69-94. https://doi.org/10.1093/schbul/sb1060

27. Demily C, Louchart-de-la-Chapelle S, Nkam I, Ramoz N, Denise P, Nicolas A, Savalle C, Thibaut F (2016) Does COMT val158met polymorphism influence P50 sensory gating, eye tracking or saccadic inhibition dysfunctions in schizophrenia? Psychiatry Res 246:738-744. https://doi.org/10.1016/j.psychres.2016.07.066

28. Ettinger U, Kumari V, Collier DA, Powell J, Luzi S, Michel TM, Zedomi O, Williams SC (2008) Catechol-O-methyltransferase (COMT) val158met genotype is associated with BOLD response as a function of task characteristic. Neuropsychopharmacol 33:3046-3057. https://doi.org/10.1038/sj.npp.1301658

29. Haraldsson HM, Ettinger U, Magnusdottir BB, Sigmundsson T, Sigurdsson E, Ingason A, Petursson H (2010) Catechol-Omethyltransferase Val158Met polymorphism and antisaccade eye movements in schizophrenia. Schizophr Bull 36:157-164. https://doi.org/10.1093/schbul/sbn064

30. Kattoulas E, Evdokimidis I, Stefanis NC, Avramopoulos D, Stefanis CN, Smyrnis N (2010) Monitoring antisaccades: inter-individual differences in cognitive control and the influence of COMT and DRD4 genotype variations. Exp Brain Res 203:453-463. https://doi.org/10.1007/s00221-010-2250-2

31. Dickinson D, Elvevåg B (2009) Genes, cognition and brain through a COMT lens. Neuroscience 164:72-87. https://doi. org/10.1016/j.neuroscience.2009.05.014

32. Lin JR, Cai Y, Zhang Q, Zhang W, Nogales-Cadenas R, Zhang ZD (2016) Integrated post-GWAS analysis sheds new light on the disease mechanisms of schizophrenia. Genetics. 204(4):1587-1600. https://doi.org/10.1534/genetics.116.187195

33. Boyle EA, Li YI, Pritchard JK (2017) An expanded view of complex traits: from polygenic to omnigenic. Cell 169(7):11771186. https://doi.org/10.1016/j.cell.2017.05.038

34. Tunbridge EM, Harrison PJ, Weinberger DR (2006) Catecholo-methyltransferase, cognition, and psychosis: Val158Met and beyond. Biol Psychiatry 60:141-151. https://doi.org/10.1016/j. biopsych.2005.10.024

35. Chen J, Lipska BK, Halim N, Ma QD, Matsumoto M, Melhem S, Kolachana BS, Hyde TM, Herman MM, Apud J, Egan MF, Kleinman JE, Weinberger DR (2004) Functional analysis of genetic variation in catechol-O-methyltransferase (COMT): effects on mRNA, protein, and enzyme activity in postmortem human brain. Am J Hum Genet 75:807-821. https://doi. org $/ 10.1086 / 425589$

36. Meyer-Lindenberg A, Nichols T, Callicott H, Ding J, Kolachana B, Buckholtz J, Mattat VS, Egan M, Weinberger DR (2006) Impact of complex genetic variation in COMT on human brain function. Mol Psychiatry 11:867-877. https://doi.org/10.1038/ sj.mp. 4001860

37. Heinz A, Smolka MN (2006) The effects of catechol O-methyltransferase genotype on brain activation elicited by affective stimuli and cognitive tasks. Rev Neurosci 17:359-367. https:// doi.org/10.1515/REVNEURO.2006.17.3.359

38. McIntosh AM, Baig BJ, Hall J, Job D, Whalley HC, Lymer GK, Moorhead TW, Owens DG, Miller P, Porteous D, Lawrie SM, Johnstone EC (2007) Relationship of catechol-O-methyltransferase variants to brain structure and function in a population at high risk of psychosis. Biol Psychiatry 61:1127-1134. https://doi. org/10.1016/j.biopsych.2006.05.020

39. Ohnishi $\mathrm{T}$, Hashimoto R, Mori $\mathrm{T}$, Nemoto $\mathrm{K}$, Moriguchi $\mathrm{Y}$, Iida H, Noguchi H, Nakabayashi T, Hori H, Ohmori M, Tsukue R, Anami K, Hirabayashi N, Harada S, Arima K, Saitoh O, Kunugi H
(2006) The association between the Val158Met polymorphism of the catechol-O-methyl transferase gene and morphological abnormalities of the brain in chronic schizophrenia. Brain 129:399-410. https://doi.org/10.1093/brain/awh702

40. Lew SE, Tseng KY (2014) Dopamine modulation of GABAergic function enables network stability and input selectivity for sustaining working memory in a computational model of the prefrontal cortex. Neuropsychopharmacology 39(13):3067-3076. https://doi. org/10.1038/npp.2014.160

41. Akbarian S, Huang HS (2006) Molecular and cellular mechanisms of altered GAD1/GAD67 expression in schizophrenia and related disorders. Brain Res Rev 52:293-304. https://doi.org/10.1016/j. brainresrev.2006.04.001

42. Benes FM. Berretta S (2001) GABAergic interneurons: implications for understanding schizophrenia and bipolar disorder. Neuropsychopharmacology 25:1-27. https://doi.org/10.1016/S0893 $-133 X(01) 00225-1$

43. Fung SJ, Webster MJ, Sivagnanasundaram S, Duncan C, Elashoff M, Weickert CS (2010) Expression of interneuron markers in the dorsolateral prefrontal cortex of the developing human and in schizophrenia. Am J Psychiatry 167:1479-1488. https://doi. org/10.1176/appi.ajp.2010.09060784

44. Hashimoto T, Arion D, Unger T, Maldonado-Avilés JG, Morris HM, Volk DW, Mirnics K, Lewis DA (2008) Alterations in GABA-related transcriptome in the dorsolateral prefrontal cortex of subjects with schizophrenia. Mol Psychiatry 13:147-161. https ://doi.org/10.1038/sj.mp.4002011

45. Lewis DA, Hashimoto T, Volk DW (2005) Cortical inhibitory neurons and schizophrenia. Nat Rev Neurosci 6:312-324. https:// doi.org/10.1038/nrn1648

46. Torrey EF, Barci BM, Webster MJ, Bartko JJ, Meador-Woodruff JH, Knable MB (2005) Neurochemical markers for schizophrenia, bipolar disorder, and major depression in postmortem brains. Biol Psychiatry 57:252-260. https://doi.org/10.1016/j.biops ych.2004.10.019

47. Volk DW, Sampson AR, Zhang Y, Edelson JR, Lewis DA (2016) Cortical GABA markers identify a molecular subtype of psychotic and bipolar disorders. Psychol Med 46:2501-2512. https://doi. org/10.1017/S0033291716001446

48. Addington AM, Gornick M, Duckworth J, Sporn A, Gogtay $\mathrm{N}$, Bobb A, Greenstein D, Lenane M, Gochman P, Baker N, Balkissoon R, Vakkalanka RK, Weinberger DR, Rapoport JL, Straub RE (2005) GAD1 (2q31.1), which encodes glutamic acid decarboxylase (GAD67), is associated with childhood-onset schizophrenia and cortical gray matter volume loss. Mol Psychiatry 10:581-588. https://doi.org/10.1038/sj.mp.4001599

49. Brauns S, Gollub RL, Walton E, Hass J, Smolka MN, White T, Wassink TH, Calhoun VD, Ehrlich S (2013) Genetic variation in GAD1 is associated with cortical thickness in the parahippocampal gyrus. J Psychiatr Res 47:872-879. https://doi.org/10.1016/j. jpsychires.2013.03.010

50. Straub RE, Lipska BK, Egan MF, Goldberg TE, Callicott JH, Mayhew MB, Vakkalanka RK, Kolachana BS, Kleinman JE, Weinberger DR (2007) Allelic variation in GAD1 (GAD67) is associated with schizophrenia and influences cortical function and gene expression. Mol Psychiatry 129:854-869. https://doi. org/10.1038/sj.mp.4001988

51. Lett TA, Kennedy JL, Radhu N, Dominguez LG, Chakravarty MM, Nazeri A, Farzan F, Walter H, Heinz A, Mulsant BH, Daskalakis ZJ, Voineskos AN (2016) Prefrontal white matter structure mediates the influence of GAD1 on working memory. Neuropsychopharmacology 41:2224-2231. https://doi. org/10.1038/npp.2016.14

52. De Young CG, Clark R (2012) The gene in its natural habitat: the importance of gene-trait interactions. Devel Psychopathol 24:1307-1318. https://doi.org/10.1017/S0954579412000727 
53. Biederman J, Kim JW, Doyle AE, Mick E, Fagerness J, Smoller JW, Faraone SV (2008) Sexually dimorphic effects of four genes (COMT, SLC6A2, MAOA, SLC6A4) in genetic associations of ADHD: A preliminary study. Am J Med Genet B Neuropsychiatr Genet 147B:1511-1518. https://doi.org/10.1002/ajmg.b.30874

54. Tucker DM, Williamson PA (1984) Asymmetric neural control system in human self-regulation. Psychol Review 91:185-215 N 1

55. Swerdlow NR, Light GA, Sprock J, Calkins ME, Green MF, Greenwood TA, Gur RE, Gur RC, Lazzeroni LC, Nuechterlein KH, Radant AD, Ray A, Seidman LJ, Siever LJ, Silverman JM, Stone WS, Sugar CA, Tsuang DW, Tsuang MT, Turetsky BI, Braff DL (2014) Deficient prepulse inhibition in schizophrenia detected by the multi-site COGS. Schizophr Res 152:503-512. https://doi. org/10.1016/j.schres.2013.12.004

56. Hoenicka J, Garrido E, Martínez I, Ponce G, Aragüés M, Rodríguez-Jiménez R, España-Serrano L, Alvira-Botero X, Santos JL, Rubio G, Jiménez-Arriero M, Palomo T (2010) Genderspecific COMT Val158Met polymorphism association in spanish schizophrenic patients. Am J Med Genet B Neuropsychiatr Genet 153B(1):79-85. https://doi.org/10.1002/ajmg.b.30957

57. Costas J, Sanjuán J, Ramos-Ríos R, Paz E, Agra S, Ivorra JL, Páramo M, Brenlla J, Arrojo M (2011) Heterozygosity at catecholO-methyltransferase Val158Met and schizophrenia: new data and meta-analysis. J Psychiatr Res 45:7-14. https://doi.org/10.1016/j. jpsychires.2010.04.021

58. Smyrnis N, Evdokimidis I, Stefanis NC, Avramopoulos D, Constantinidis TS, Stavropoulos A, Stefanis CN (2003) Antisaccade performance of 1,273 men: effects of schizotypy, anxiety, and depression. J Abnorm Psychol 112:403-414. https://doi. org/10.1037/0021-843X.112.3.403

59. Smyrnis N, Karantinos T, Malogiannis I, Theleritis C, Mantas A, Stefanis NC, Hatzimanolis J, Evdokimidis I (2009) Larger variability of saccadic reaction times in schizophrenia patients. Psychiatry Res 168:129-136. https://doi.org/10.1016/j.psych res.2008.04.015

60. Karantinos T, Tsoukas E, Mantas A, Kattoulas E, Stefanis NC, Evdokimidis I, Smyrnis N (2014) Increased intra-subject reaction time variability in the volitional control of movement in schizophrenia. Psychiatry Res 215:26-32. https://doi.org/10.1016/j. psychres.2013.10.031

61. Schall JD (2002) The neural selection and control of saccades by the frontal eye field. Phil. Trans Roy Soc Lond B 357(1424):10731082. https://doi.org/10.1098/rstb.2002.1098

62. Fukushima J, Morita N, Fukushima K, Chiba T, Tanaka S, Yamashita I (1990) Voluntary control of saccadic eye movements in patients with schizophrenic and affective disorders. J Psychiatr Res 24:9-24. https://doi.org/10.1016/0022-3956(90)90021-H

63. Slavutskaya MV, Kirenskaya AV, Kozlovskaya IB (2005) Novototskiı̌-Vlasov VYu, Shul'govskiĭ VV. Slow potentials of the brain before saccades in response to visual stimuli in schizophrenic patients. Hum Physiol 31:545-553. https://doi. org/10.1007/s10747-005-0095-z

64. Gale HJ, Holzman PS (2000) A new look at reaction time in schizophrenia. Schizophr Res 46:149-165. https://doi.org/10.1016/ S0920-9964(00)00006-2

65. Curtis CE, Calkins ME, Iacono WG (2001) Saccadic disinhibition in schizophrenia patients and their first-degree biological relatives. A parametric study of the effects of increasing inhibitory load. Exp Brain Res 137:228-236. https://doi.org/10.1007/s002210000 635

66. Kirenskaya AV, Storozheva ZI, Kolobov VV, Sherstnev VV (2015) The acoustic startle response and polymorphism of the gene for catechol-O-methyltransferase in the norm and in schizophrenia. Neurochem J 9(1):76-83. https://doi.org/10.1134/S181971241 5010031 